\title{
B7-H3 in cancer - beyond immune regulation
}

Karine Flem-Karlsen ${ }^{1,2}, \varnothing_{\text {ystein Fodstad }}{ }^{1,2}$, Ming Tan $^{3}$ and Caroline E. Nunes-Xavier ${ }^{1}$

Department of Tumor Biology, Institute for Cancer Research, Oslo University

Hospital Radiumhospitalet, Oslo, Norway.

${ }^{2}$ Institute for Clinical Medicine, Faculty of Medicine, University of Oslo, Oslo,

Norway.

${ }^{3}$ Center for Cell Death and Metabolism, Mitchell Cancer Institute, University of South Alabama, Mobile, Alabama. Department of Biochemistry and Molecular Biology, University of South Alabama, Mobile, Alabama

*Correspondence: Caroline E. Nunes-Xavier, PhD, Department of Tumor Biology, Institute for Cancer Research, Oslo University Hospital Radiumhospitalet, P.O. Box 4950 Nydalen, N-0424 Oslo, Norway. Phone: +4722781875 Email: caroliten@gmail.com 


\begin{abstract}
B7-H3, a member of the B7 family of immunoregulatory proteins, is overexpressed in cancers and promotes tumor growth, metastasis and drug resistance. Here, we discuss the involvement of B7-H3 in cancer that goes beyond its immune regulatory function, and discuss the potential of B7-H3 as a biomarker and therapeutic target.
\end{abstract}

With the successful introduction of checkpoint inhibitors in cancer treatment, the B7 family of proteins is receiving increasing attention. B7 proteins bind to members of the CD28/CTLA-4 family which operate as the costimulatory signal in the activation of $\mathrm{T}$ cells. Without this additional stimulation signal, T cell activation may lead to cell death. B7 family members are classified as i) co-stimulatory, ii) co-inhibitory, or dually as iii) co-stimulatory and co-inhibitory, depending on the effects they induce in T-cell activation through CD28 signaling. For instance, B7-H3 related protein, PD-L1/B7-H1, is the inhibitory ligand of PD-1 death receptor in immune cells, leading to reduced T cell proliferation, and this provides the rationale for targeting both proteins in cancer. B7-H3 was initially characterized as a T-cell stimulating protein, but the majority of current studies describe B7-H3 as a T-cell inhibitor that promotes tumor aggressiveness and proliferation. This suggests that B7-H3 may be an important immunological target in cancer [1], and underlies a need for studies that elucidate further its role in immune regulation, including the identification of B7-H3 binding partners. Importantly, B7-H3 is also emerging as a protein that regulates tumor growth, metastasis and drug sensitivity independently of the immune system.

\title{
Expression and regulation of $\mathrm{B} 7-\mathrm{H} 3$ in cancer
}

Expression of B7-H3 mRNA is found in a wide range of normal human tissues, but B7$\mathrm{H} 3$ protein is expressed at low levels, suggesting a tight post-transcriptional regulation. In contrast, the B7-H3 protein is overexpressed in many types of malignancies, and is linked to poor prognosis, increased tumor grade and metastasis, resistance to therapy, and decreased overall survival.

The human B7-H3 protein exists either as a transmembrane or soluble isoform. Transmembrane B7-H3 is mainly found at the surface of tumor cells, but also in 
cytoplasmic vesicles and the nucleus. The nuclear localization is associated with poor outcome in colon cancer [2]. High-levels of soluble isoform are detected in the serum of cancer patients [3], which suggests soluble B7-H3 as a potential non-invasive biomarker. Finally, B7-H3 protein has also been found in the secretome, including exosomes and other extracellular vesicles [4].

B7-H3 is also expressed in tumor-associated endothelial cells, and high expression levels are associated with advanced tumor grade. Expression of B7-H3 in the tumor vasculature was recently exploited to improve the accuracy of a breast cancer diagnostic [5]. Preclinical radioimmunotherapy in ovarian cancer using B7-H3 antibodies radiolabeled with $212 \mathrm{~Pb} \alpha$-particles target tumor cells and vasculature and showed promising effects with low toxicity [6]. In addition, an antibody targeting B7-H3 conjugated with the DNA alkylating compound Pyrrolobenzodiazepine was shown to target both B7-H3 expressing tumor cells and vasculature [7]. High expression of B7$\mathrm{H} 3$ in tumor vasculature may also contribute to the formation of pre-metastatic niches and facilitate metastasis. Expression of VEGF (vascular endothelial growth factor) in tumor cells was found mediated by sB7-H3 [3], thus combination of anti-B7-H3 and anti-VEGF drugs might be a valuable combinatorial therapeutic approach.

\section{B7-H3 induces pro-oncogenic traits such as cell growth and metastasis}

Knocking down expression or inhibiting B7-H3 decreases the growth of many types of cancer cells in vitro and in vivo. Also, the potential of adhesion, migration, invasion and metastasis of cancer cells is affected by B7-H3 expression levels [3, 6-8]. An increasing number of studies support a pro-oncogenic role for B7-H3 in various types of cancer that is independent of its immune function.

How B7-H3 promotes tumors is not independently of the immune system completely understood, but B7-H3 seems to act upstream to activate signaling routes, such as JAK/STAT and PI3K/Akt pathways, to induce anti-apoptotic and proliferative mechanisms $[9,10]$. B7-H3 modulates the expression of cytokines and metalloproteinases involved in metastasis, such as IL-8, MMP-2, TIMP-1 and TIMP-2 through the PI3K/Akt and NF-kappa B pathways (Figure 1). B7-H3 expression was also recently shown to inhibit the transcription factor NRF2, leading to increased reactive oxygenated species (ROS) and HIF1 $\alpha$ levels, thus inducing aerobic glycolysis 
leading to tumor growth [11]. If these tumor promoting effects of $\mathrm{B} 7-\mathrm{H} 3$ are due to signaling triggered from the extracellular domain of B7-H3 is yet to be determined.

Since exosomes can travel and fuse to distant cells, cancer-derived exosomal B7-H3 may be transferred to stromal or tumors cells. Increasing B7-H3 signaling in the recipient cells by exosomes could activate the downstream signaling pathways of B7$\mathrm{H} 3$ in the exosome-receiving cell, for example the aforementioned JAK/STAT and PI3K/Akt pathways, and thus induce proliferation, metastasis or resistance to therapy. In this manner, soluble B7-H3 isoforms can also contribute to increased invasion and metastasis capacity.

B7-H3 also promotes resistance to cancer drugs. A growing number of studies show that inhibition or reduced expression of B7-H3 increases the response of tumor cells to drugs that target DNA replication, alkylating agents, and inhibitors of PI3K/Akt/mTOR and Ras/Raf/MEK signaling [4, 6, 9, 10]. This further supports B7-H3 as a target in anticancer therapy, alone or in combination with other existing therapeutic modalities.

\section{Concluding remarks}

The differential expression of $\mathrm{B} 7-\mathrm{H} 3$ in tumors versus healthy tissues makes targeting of B7-H3 particularly attractive, potentially with limited side effects. The efficacy of inhibiting B7-H3 activity was evaluated in preclinical studies with short hairpin RNAs, RNA interference, or anti-B7-H3 monoclonal antibodies. Inhibition or reduction of B7H3 protein expression decreased proliferation and glycolysis and increased drug sensitivity in tumor cells. Currently, there are several clinical trials targeting B7-H3 (Table 1). The first results from a clinical trial with enoblituzumab (MGA271; anti-B7$\mathrm{H} 3 \mathrm{Ab}$ ) show, antitumor-properties and increased $\mathrm{T}$ cell repertoire with no doselimiting toxicity and no severe immune-related side effects [12]. Clinical studies combining anti-B7-H3 antibodies with chemotherapy, small molecule inhibitors of $\mathrm{PI} 3 \mathrm{~K} / \mathrm{Akt} / \mathrm{mTOR}$ and Raf/MEK pathways, or with immune checkpoint inhibitors, may establish B7-H3 as a therapeutic target in cancer treatment as a synergistic antitumor approach or to enhance immune response respectively. 


\section{References}

1. Picarda, E. et al. (2016) Molecular Pathways: Targeting B7-H3 (CD276) for Human Cancer Immunotherapy. Clin Cancer Res 22 (14), 3425-31.

2. Ingebrigtsen, V.A. et al. (2012) B7-H3 expression in colorectal cancer: nuclear localization strongly predicts poor outcome in colon cancer. Int J Cancer 131 (11), 2528-36.

3. Xie, C. et al. (2016) Soluble B7-H3 promotes the invasion and metastasis of pancreatic carcinoma cells through the TLR4/NF-kappaB pathway. Sci Rep 6, 27528.

4. Flem-Karlsen, K. et al. (2017) Immunoregulatory protein B7-H3 promotes growth and decreases sensitivity to therapy in metastatic melanoma cells. Pigment Cell Melanoma Res 30 (5), 467-476.

5. Bachawal, S.V. et al. (2015) Breast Cancer Detection by B7-H3-Targeted Ultrasound Molecular Imaging. Cancer Res 75 (12), 2501-9.

6. Kasten, B.B. et al. (2017) B7-H3-targeted $212 \mathrm{~Pb}$ radioimmunotherapy of ovarian cancer in preclinical models. Nucl Med Biol 47, 23-30.

7. Seaman, S. et al. (2017) Eradication of Tumors through Simultaneous Ablation of CD276/B7-H3Positive Tumor Cells and Tumor Vasculature. Cancer Cell 31 (4), 501-515 e8.

8. Tekle, C. et al. (2012) B7-H3 contributes to the metastatic capacity of melanoma cells by modulation of known metastasis-associated genes. Int J Cancer 130 (10), 2282-90.

9. Liu, H. et al. (2011) B7-H3 silencing increases paclitaxel sensitivity by abrogating Jak2/Stat3 phosphorylation. Mol Cancer Ther 10 (6), 960-71.

10. Nunes-Xavier, C.E. et al. (2016) Decreased expression of B7-H3 reduces the glycolytic capacity and sensitizes breast cancer cells to AKT/mTOR inhibitors. Oncotarget 7 (6), 6891-901.

11. Lim, S. et al. (2016) Immunoregulatory Protein B7-H3 Reprograms Glucose Metabolism in Cancer Cells by ROS-Mediated Stabilization of HIF1alpha. Cancer Res 76 (8), 2231-42.

12. Powderly, J. et al. (2015) Interim results of an ongoing Phase I, dose escalation study of MGA271

(Fc-optimized humanized anti-B7-H3 monoclonal antibody) in patients with refractory B7-H3expressing neoplasms or neoplasms whose vasculature expresses B7-H3. J Immunother Cancer 3(Suppl 2) (O8). 


\section{Figure legend}

FIGURE 1. Schematic overview of B7-H3 signaling in the tumor cell. Much is still unknown of how B7-H3 exerts signaling that induce cell survival and proliferation. However, the displayed pathways have been shown to be involved. B7-H3, present on antigen presenting cells or tumor cells, is activated by soluble or exosomal B7-H3 or by an unknown protein present on $\mathrm{T}$ cells or other tumor cells. This activation will, indirectly, activate NFxB, PI3K/Akt and JAK/STAT3 pathways to induce cell survival and proliferation. B7-H3 activation will also inhibit NRF2, leading to increased ROS and HIF1 $\alpha$ levels, leading to increased glycolysis. sB7-H3: soluble B7-H3. ROS: reactive oxygen species. Green arrow: activation, blue arrow: translocation. Red arrow: inhibition.

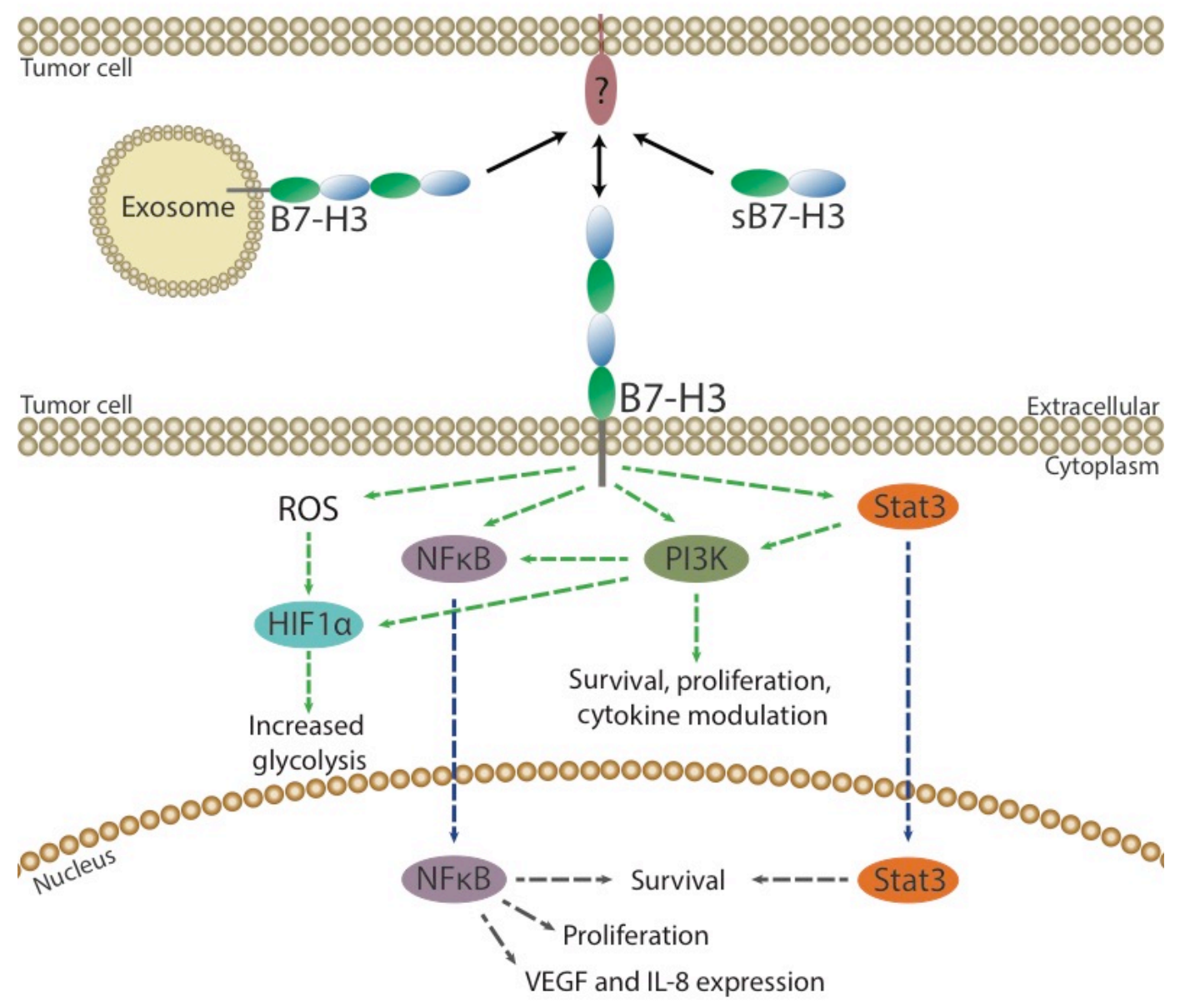




\begin{tabular}{|c|c|c|c|}
\hline Identifier \# & Agent/drug & Brief trial description & $\begin{array}{l}\text { Status and/or } \\
\text { Estimated Study } \\
\text { Completion } \\
\text { nate }\end{array}$ \\
\hline $\begin{array}{l}\text { NCT0262853 } \\
5\end{array}$ & MGD009 & B7-H3-expressing tumors & $\begin{array}{l}\text { Recruiting } \\
\text { December } 2020\end{array}$ \\
\hline $\begin{array}{l}\text { NCT0298294 } \\
1\end{array}$ & Enoblituzumab ${ }^{1}$ & $\begin{array}{l}\text { Children With B7-H3-expressing } \\
\text { Solid Tumors }\end{array}$ & $\begin{array}{l}\text { Recruiting } \\
\text { February } 2022\end{array}$ \\
\hline $\begin{array}{l}\text { NCT0139114 } \\
3\end{array}$ & Enoblituzumab & $\begin{array}{l}\text { B7-H3-expressing refractory } \\
\text { cancer }\end{array}$ & $\begin{array}{l}\text { Recruiting } \\
\text { June } 2018\end{array}$ \\
\hline $\begin{array}{l}\text { NCT0247521 } \\
3\end{array}$ & $\begin{array}{l}\text { Enoblituzumab } \\
+\end{array}$ & $\begin{array}{l}\text { B7-H3-expressing refractory } \\
\text { cancer }\end{array}$ & $\begin{array}{l}\text { Recruiting } \\
\text { August } 2020\end{array}$ \\
\hline $\begin{array}{l}\text { NCT0238131 } \\
4\end{array}$ & $\begin{array}{l}\text { Enoblituzumab } \\
+ \text { + pilimumab }\end{array}$ & $\begin{array}{l}\text { B7-H3-expressing refractory } \\
\text { cancer }\end{array}$ & $\begin{array}{l}\text { Recruiting } \\
\text { September }\end{array}$ \\
\hline NCT0191893 & Enoblituzumab & Melanoma & Terminated \\
\hline $\begin{array}{l}\text { NCT0292318 } \\
0\end{array}$ & Enoblituzumab & $\begin{array}{l}\text { Localized Intermediate and High- } \\
\text { Risk Prostate Cancer }\end{array}$ & \begin{tabular}{|l|} 
Recruiting \\
October 2019 \\
\end{tabular} \\
\hline $\begin{array}{l}\text { NCT0109964 } \\
4\end{array}$ & $131 \mathrm{I}-8 \mathrm{H} 9$ & $\begin{array}{l}\text { Intraperitoneal } \\
\text { Radioimmunotherapy }\end{array}$ & \begin{tabular}{|l|} 
Recruiting \\
April 2018 \\
\end{tabular} \\
\hline $\begin{array}{l}\text { NCT0008924 } \\
5\end{array}$ & $131 \mathrm{I}-8 \mathrm{H} 9$ & $\begin{array}{l}\text { Refractory, Recurrent, or } \\
\text { Advanced CNS or Leptomeningeal }\end{array}$ & $\begin{array}{l}\text { Recruiting } \\
\text { July } 2018\end{array}$ \\
\hline $\begin{array}{l}\text { NCT0150291 } \\
7\end{array}$ & $131 \mathrm{I-}-8 \mathrm{H} 9$ & $\begin{array}{l}\text { Non-Progressive Diffuse Pontine } \\
\text { Gliomas Previously Treated With } \\
\text { External Beam Radiation Therapy }\end{array}$ & $\begin{array}{l}\text { Recruiting } \\
\text { December } 2018\end{array}$ \\
\hline $\begin{array}{l}\text { NCT0058260 } \\
8\end{array}$ & $131 \mathrm{I}-8 \mathrm{H} 9$ & $\begin{array}{l}\text { CNS cancer, neuroblastoma and } \\
\text { Sarcoma. Detection of the cancer. }\end{array}$ & $\begin{array}{l}\text { Terminated } \\
\text { Completed }\end{array}$ \\
\hline
\end{tabular}

